\title{
Lean and green supply chain management through intermodal transport: Insights from the Fast Moving Consumer Goods industry
}

\author{
Claudia Colicchia
}

University of Hull, Hull University Business School, Logistics Institute

Cottingham Road, Hull, UK, HU6 7RX

e-mail: c.colicchia@hull.ac.uk; Tel. +44 (0)1482 347550

\author{
Alessandro Creazza (corresponding author) \\ University of Hull, Hull University Business School, Logistics Institute \\ Cottingham Road, Hull, UK, HU6 7RX \\ e-mail: a.creazza@hull.ac.uk; Tel. +44 (0)1482 347586
}

Fabrizio Dallari

Logistics Research Centre, LIUC University, Castellanza, Italy

Corso Matteotti 22, 21053, Castellanza, Italy

e-mail: fdallari@liuc.it; Tel. +39 0331572268 


\title{
Lean and green supply chain management through intermodal transport: Insights from the Fast Moving Consumer Goods industry
}

\author{
Abstract \\ Combining efficiency, effectiveness, and sustainability is crucial for companies to \\ succeed in today's context of fierce competition. This paper investigates how \\ intermodal transport can be adopted for managing supply chains according to a Lean \\ and Green approach. A scenario-based estimation tool was developed to quantify the \\ potential demand for intermodal transport. The tool was applied to the Italian Fast \\ Moving Consumer Goods (FMCG) supply chain. Following, a single longitudinal case \\ study on a FMCG company (Procter \& Gamble) was carried out to investigate the \\ enabling factors for the adoption of intermodal transport. Our results show that it is \\ possible to shift demand from road to rail: a number of pathways for action were \\ identified that related to planning and management, assets, train services, collaboration, \\ legal issues, and incentive schemes. Also, a collaborative business model for making \\ the modal shift possible was presented. This paper is original because it offers an \\ investigation of Lean and Green Supply Chain Management through intermodal \\ transport by adopting a supply chain perspective and providing a bridging link between \\ academic studies and field evidence.
}

Keywords: Supply Chain Management, Green Supply Chains, Lean Systems, Intermodal Transport, Fast Moving Consumer Goods 


\section{Introduction}

In today's context of global economy and fierce competition, the "prize" will go to those companies that will excel from an efficiency, effectiveness, and sustainability perspective (Garza-Reyes 2015).

Recently, the traditional approaches of Lean Supply Chain Management (LSCM) and Green Supply Chain Management (GSCM), respectively focused on cost and waste reduction and on environmental strategies and practices, have been paired for concurrently achieving the objectives of efficiency, effectiveness, and sustainability (Garza-Reyes et al. 2016, Martínez-Jurado and Moyano-Fuentes 2014). The new resulting paradigm, Lean \& Green Supply Chain Management (L\&GSCM), has progressively gained popularity, and a number of studies to foster the adoption of this approach have been proposed (Piercy and Rich 2015).

Within L\&GSCM, a crucial role is played by transportation (Villarreal, Garza-Reyes and Kumar 2016). Companies make intense use of transport to cope with demand from their customers, and the cost share in the supply chain due to transport is significant with transportation activities being some of the main sources of greenhouse gases emissions (Piercy and Rich 2015, Ghiani, Laporte and Musmanno 2013). Within the remit of transportation, one of the main initiatives that can be undertaken to achieve the targets of L\&GSCM is the adoption of intermodal transport, given its potentialities in terms of cost and emissions reductions (Anten, Ploos van Amstel, Verweij 2014, Bhattacharya et al. 2014). This view is widely supported also by the European Commission, which has made repeated, constant efforts to facilitate the modal shift from road to intermodal road-rail transport (EngLarsson and Norrman 2014, Beskovnik and Twrdy 2012).

However, the use of road transport has reduced slightly over many years (Anten, Ploos van Amstel, Verweij 2014), and the reasons behind this phenomenon still seem underexplored (Lammgard 2012). This calls for further studies on the investigation on the adoption of 
intermodal transport initiatives along with the related challenges and enabling factors to foster a step-change in the growth of intermodal transport.

The described scenario provides the motivation of this study. The Fast Moving Consumer Goods (FMCG) supply chain is taken into account as an application example.

The remainder of this paper is organized as follows: the theoretical background is presented in Section 2, while the objective, research question, and scope of the study are outlined in Section 3. Section 4 describes the adopted research methodology. Section 5 presents and discusses the results of the study, and in Section 6 we conclude the paper by providing final remarks and future research directions.

\section{Theoretical background}

Intermodal transport can be defined as the combination of two or more different modes of transport, where the load is transported in one and the same intermodal transport unit, with most of the route travelled by rail, inland waterway, or ocean shipping (SteadieSeifi et al. 2014, Caris, Macharis and Janssens 2013). The adoption of intermodal road-rail transportation has been encouraged to reduce the $\mathrm{CO} 2$ emissions related to the movement of goods along the supply chain (Eng-Larsson and Norrman 2014).

The literature has addressed the adoption of intermodal transport solutions from different perspectives, each of them investigating the views of different stakeholders, i.e. shippers, carriers, and society (Eng-Larsson and Kohn 2012). While the perspectives of the

carriers and society have already been widely investigated, the perspective of the shippers has been overlooked (Monios 2015). Likewise, an end-to-end supply chain perspective has been neglected so far (Monios 2015, Caris, Macharis and Janssens 2013).

When addressing the adoption of intermodal transport, the literature suggests three levels of decision making, i.e. strategic, tactical, and operational (SteadieSeifi et al. 2014). Strategic planning relates to investments on infrastructures to support policy makers (e.g. 
Iannone 2012). Tactical planning deals with the optimal use of the existing infrastructure by designing intermodal services, i.e. planning itineraries and frequencies (e.g. Kreutzberger 2008). Operational planning tackles real-time requirements of multimodal operators, for optimizing routing/drayage operations (e.g. Escudero et al. 2013). A further research stream addresses information technology to manage real-time information for intermodal planning (e.g. Macharis et al. 2012). The three different levels of decision making have been investigated mainly through quantitative models. The interested reader should refer to the literature reviews published by SteadieSeifi et al. (2014) and Caris, Macharis and Janssens (2013).

Furthermore, contributions have revolved around the feasibility of the adoption of intermodal transport for the distribution of goods (Meisel, Kirschstein and Bierwirth 2013). With reference to the shift from road to rail, three groups of challenges have been identified:

- Operational and quality factors. These revolve around transit times, reliability, flexibility, order visibility, safety from damage, transparency of the actual costs, asset utilization, and break-even distance justifying the modal shift (Monios 2015). A major issue related to these factors is demonstrated by customers' perceptions of the intermodal service. Customers do not usually perceive that intermodal transport is able to satisfy the market requirements related to these factors in the delivery of the service (Woodburn 2006).

- Product-related factors. These are directly connected with the "suitability" of products for intermodal transport. They include product value, product demand profile, size and weight, and perishability (Eng-Larsson and Kohn 2012).

- Supply chain management factors. Include inventory levels, delivery windows width, planning, and ordering processes. These need to be taken into account to ensure consistency of decision making along the supply chain. There is a strong 
interdependency of the modal choice decisions on different levels in a supply chain context, which cannot be made in isolation (Eng-Larsson and Kohn 2012). Mind-set and cultural changes are needed to enable the modal shift through the development of suitable business models able to achieve a holistic view of the supply chain (Monios and Bergqvist 2015, Blome and Schuetz 2014). Cooperation and integration among supply chain partners in decision making and planning are needed to achieve economies of scale and make intermodal services profitable (Vachon and Klassen 2006). This is critical since the literature found the industry reluctant to adopt such a collaborative approach (De Langen and Van der Horst 2008). Some endeavours in this direction have investigated freight consolidation (Zhou, Van Hui and Liang 2011), collaborative intermodal hub networks (Groothedde, Ruijgrok and Tavasszy 2005) and sustainable collaborative networked organisations (Jaegler and Burlat 2012). Effective solutions can be developed especially when horizontal and vertical collaboration are combined in supply chain decisions (Mason, Lalwani and Boughton 2007).

The existing literature includes some contributions where these three groups of challenges emerge through the discussion of some cases. Maes and Vanelslander (2011) discuss the case of the French retailer Monoprix, centred on the adoption of intermodal transport in an urban logistics context, where the existing sub-urban rail transport lines are used to approach the city distribution hubs. In this case the viability of the intermodal transport is connected to product-related factors (bulky and heavy products such as bottled drinks) with a specific emphasis on non-time-sensitive requirements that accommodate the use of existing shared transport lines. Monios (2015) focuses on the use of intermodal transport in the UK retail sector, involving in the study major retailers, logistics service providers and transport operators. Findings from this work highlight that in the studied sample only the largest retailer 
(Tesco) is successful in directly arranging and establishing the intermodal service by loading complete trains and by having a dedicated service rather than buying space on a service provided by a third party. In this example operational and product-related factors are key to determine the feasibility of the modal shift: in particular the author discusses how intermodal transport is usable for non-time-sensitive products when moved on sufficient distances, with balanced flows in both directions, and when assets can be well utilised. The cases of the other retailers (such as ASDA and Sainsbury's) need to rely on transport providers to consolidate flows and achieve a critical mass justifying the use of rail. Given the necessity to aggregate flows to achieve the critical mass, these cases stress the need for a pervasive approach, which would imply also the establishment of horizontal collaborative relationships that would help in overcoming the abovementioned operational issues and support the development of intermodal transport. Along these lines, supply chain management factors are also discussed by Groothedde, Ruijgrok and Tavasszy (2005). Their work focuses on the FMCG in the Netherlands and provides a test of collaborative multimodal networks, involving in a pilot study retail organizations and manufacturing companies. Consolidation of flows from different companies in a collaborative environment is needed to facilitate the modal shift, especially for those sectors such as the FMCG characterized by high delivery frequencies with small shipments sizes.

It also appears from the literature that understanding the potential demand for intermodal transport is essential to investigate the feasibility and profitability of the modal shift for supply chain players (Lammgard 2012, Woodburn 2006). This would better connect the supply and demand of intermodal transport services. Otherwise, demand inertia would inhibit investments among intermodal operators. This would create a condition of low service quality and demand stagnating on the same low level (Eng-Larsson and Norrman 2014). 
To overcome these challenges, a supply chain perspective is needed. Complex relations where several supply chain partners interact should be studied, and real implementation experiences should be shared (Eng-Larsson and Norrman 2014, Lammgard 2012). The existing contributions describing examples of adoption of intermodal transport call for further investigations on the factors affecting the feasibility of the modal shift. A bridging link between academic studies and their practical test, validation, and implementation is claimed in order to provide the academic and industrial communities with further insights on the adoption of intermodal transport solutions in practice (Cheng et al. 2013). This would also help companies have a better understanding of the potentialities of intermodal transport and the related enabling factors for improving their efficiency, effectiveness, and environmental performance according to the L\&GSCM paradigm.

\section{Objective, research question, and scope of the study}

The objective of this research is to investigate how companies can adopt intermodal transport for managing their supply chain according to an L\&GSCM approach.

We aim at providing an answer to the following research question:

"How is it possible to make the modal shift from road to rail actually feasible by connecting the supply and demand of intermodal transport along the supply chain?"

The starting point is to provide an estimation of the potential demand for intermodal transport. This represents a fundamental stepping stone for breaking the "vicious circle" described in the literature, according to which demand inertia prevents from investments among operators, and in turn demand remains low with lack of investments.

Second, it is necessary to investigate from a practical perspective the challenges and enabling factors for companies in the adoption of intermodal transport, providing useful insights for making the modal shift real from a supply chain perspective. 
We focus on the FMCG supply chain as an application example. Among the different sectors heavily relying on transportation, the FMCG industry constitutes a large part of consumers' budget in all countries. Retail trade has attracted considerable interest from consumers and policy-makers because a well-functioning retail sector is crucial for daily provision of essential products at high quality and low cost (Bourlakis and Weightman 2004). It is furthermore widely-recognised that the FMCG supply chain represents a key industry to achieve a step-change in transport efficiency, because of the size of the logistics flows generated and traditionally moved by road (Fernie, Sparks and McKinnon 2010). Increased competition is creating pressure on retailers to simultaneously control cost and improve customer service (Fernie and Sparks 2014) while reducing the environmental impact of their activities (Monios 2015). This is particularly challenging for the FMCG supply chain as the last few years have witnessed a tendency toward more demanding service level leading to higher delivery frequencies with smaller shipments sizes and consequent fragmentation of flows (Fernie and Sparks 2014). Hence, the L\&GSCM approach seems particularly relevant to the FMCG sector where the modal shift can potentially ensure significant benefits. To conduct the empirical investigation, the paper focuses on the Italian FMCG supply chain.

The Italian FMCG sector constitutes a representative application field given its relevance internationally. In fact, the Italian FMCG sector is among the top four markets in Europe in terms of turnover and generated flows, and it had the second highest growth after Spain in 2016 (Nielsen 2016). It shows a level of fragmentation of the overall retail market higher that other major European markets such as the UK, Germany, France and Spain (Fornari et al. 2013). This is also due to the geographical conformation of the Italian territory, which affects how consumer are distributed across the peninsula and its two major islands. Notwithstanding this feature, it is possible to recognize in the Italian FMCG supply chain the 
presence of a few major retailers with a considerable concentration of the market shares, similarly to the other main European markets (source: IRI Group data 2015). Additionally, the Italian FMCG market is witnessing a constant trend towards the alignment to the concentration levels of the market shares typical of other European countries (Dallari et al. 2015). Over the last 20-30 years, the Italian FMCG supply chain has undergone a supply chain transformation, similarly to other European countries, including the adoption of Efficient Consumer Response principles and well-established underpinning IT technologies, such as EDI and internet-based information exchange tools. The supply chain transformation regarded also the restructuring of logistics networks including the rationalisation of the primary transportation, with retailers extending their control upstream with the introduction of distribution centres (Dallari et al. 2015, Fernie, Sparks and McKinnon 2010, Fernie and Staines 2001). Some efforts for increasing the efficiency level of the FMCG supply chain have been also undertaken with alternative transport solutions such as intermodal transport. However, similarly to the abovementioned cases of use of intermodality in UK and France in the FMCG industry, these efforts have a limited scope in terms of involved products and flows. These regarded especially individual relationships between a (large) manufacturer and a retailer, or the management of intercompany transportation within the manufacturers' logistics networks: see for example the case of Sanpellegrino Group - Nestle' Waters for the intermodal transportation of bottled drinks (Freight Leaders Council 2016).

\section{Methodology}

We adopted a two-fold methodology, combining a quantitative and a qualitative approach. This can provide a range of insights in the investigation of complex logistics and supply chain management problems (Mangan, Lalwani and Gardner 2004). 
First, a scenario-based estimation tool was developed to provide a quantification of the potential demand for intermodal transport, in terms of freight movements potentially transferable from road to rail. The tool was applied to the Italian FMCG supply chain.

Second, a single longitudinal case study on a primary company operating in the FMCG industry was performed to investigate the challenges and enabling factors in the adoption of intermodal transport.

\subsection{The scenario-based estimation tool: design and development}

The key elements of the developed scenario-based estimation tool are depicted in Figure 1.

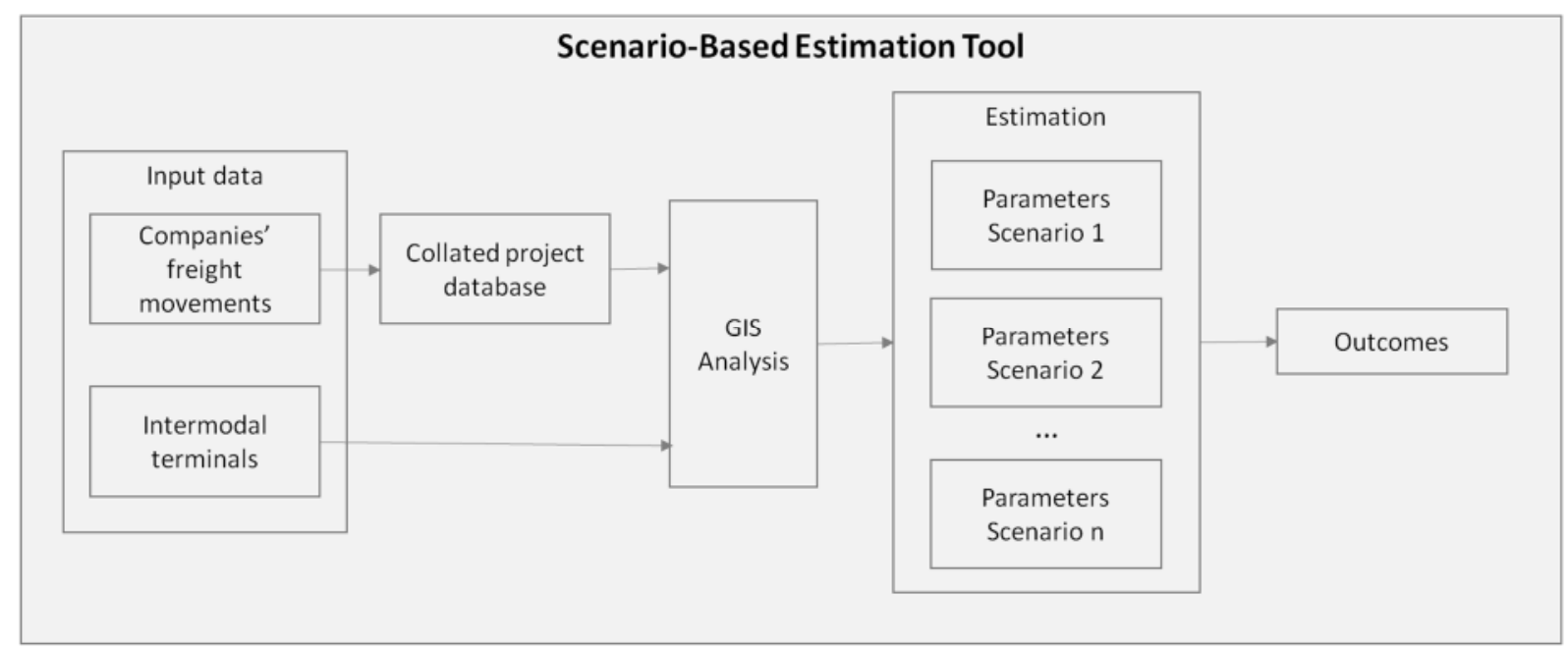

Figure 1 - The Scenario-Based Estimation Tool

The starting point is represented by the creation of a collated database of freight movements in terms of road shipments. The input data must also include the location of the intermodal terminals taken into account as hubs of origin and destination of the potential intermodal flows. Data need then to be geo-referenced (through a Geographical Information System, GIS) to associate the geographical coordinates to each single point of origin and 
destination of the flows. The geo-referenced input data need to be aggregated to estimate the potential feasible intermodal shipments, and this must happen satisfying geographic origin/destination and service level requirements. The aggregation engine is represented by a Visual Basic for Applications (VBA) algorithm that is able to generate scenarios of analysis by modifying parameters concerning the spatial and temporal features of the shipments.

The spatial parameters are:

- the size (i.e. radius) of the catchment area of each considered origin/destination (O/D) $\operatorname{area}(\mathrm{X}, \mathrm{Y})[\mathrm{km}]$;

- the minimum distance from the point of origin to the point of destination (Dmin) [km]. Alternatively, the estimation tool allows defining the spatial requirements in terms of the following parameter:

- the percentage split between the rail segment length (Df) and the overall travel distance $(\mathrm{Df}+\mathrm{x}+\mathrm{y})$ which justifies the modal shift, where $\mathrm{x}$ and $\mathrm{y}$ respectively represent the drayage segments [\%].

In this way, the user gains flexibility in defining different scenarios of analysis depending on the information available to the company: Companies might have more information on the size of the catchment area and the minimum distance from the point of origin to the point of destination, or might prefer to focus on determining the "intensity" of the use of the rail service.

The temporal parameter is related to:

- The service level performance, i.e. required order-to-delivery lead-time associated with each potential road-rail shipment (LTmin) [days]. The minimum lead-time is representative of the possibility to take into account for the rail transport all those 
shipments characterized by an order-to-delivery lead-time equal or greater than the selected number of days.

The output of the algorithm is the number of freight movements in each origin/destination region (i.e. catchment areas of the hubs) that can be potentially shifted from road to rail each week, expressed in the weekly flow of Intermodal Loading Units (ILUs). As a final outcome, the most relevant origin/destination relations are identified.

With reference to our domain of application, we took into account the typical FMCG supply chain, which relies on a logistics network including manufacturers' facilities, i.e. production plants and warehouses, and retailers' facilities (meaning, distribution centres and stores) (Fernie and Sparks 2014).

To embrace the supply chain dynamics that go beyond the dyadic relationships among manufacturers and retailers, we included also third-party logistics service providers (3PL). 3PLs are in charge of the management/execution of the activities at manufacturers' and/or retailers' logistics facilities. The extent of the involvement of the 3PLs in the management of the flows depends on the relationships with manufacturers. If the latter outsource not only the execution of the physical distribution activities but also the planning of those activities to the logistics provider, the role of the 3PLs will be such that it must not be neglected (Monios 2015).

A working group involving GS1 Italy Indicod-ECR and primary companies operating in the FMCG sector in Italy was established, including manufacturers, retailers, and thirdparty logistics service providers. This allowed adopting an end-to-end supply chain perspective and being able to access real data regarding the FMCG shipments. The project database was built through a data gathering activity from 13 manufacturers, 3 retailers and 2 logistics service providers. These 18 companies, being the major players of the Italian FMCG supply chain also from a geographical coverage viewpoint, constitute $10 \%$ of all Italian 
FMCG road freight movements (Dallari et al. 2015). Following the directions of the working group, the estimation tool has encompassed:

- Full Truck Load freight movements

- organized by companies in a 12-month time frame

- for dry food and non-food products

- performed by means of articulated heavy good vehicles

- on point-to-point single-drop relations

- originating from a manufacturer's warehouse and directed to a retailer's distribution centre/point of sale; or originating from a retailer's distribution centre and directed to a retailer's regional distribution centre/point of sale.

A focus group involving the sample companies was organized to define a common template for data gathering that avoided the double counting of freight movements (Morgan 1988). Data were then collated in a database containing around 160,000 road freight movements (Table 1). Taking into account the network of the Italian freight villages, the working group identified 9 areas as the most relevant points of origin/destination of the FMCG flows (Bari, Bologna, Catania, Milano, Nola-Naples, Novara, Padova, Pescara, and Pomezia-Rome). Data were geo-referenced adopting a postal-code level of detail.

The working group indicated two scenarios of analysis to be taken into account to estimate the potential demand for intermodal transport in the Italian FMCG supply chain (see Section 5.1).

Table 1 - The summary of the collated database (*Double counting excluded)

\begin{tabular}{|l|c|c|c|c|}
\hline & Companies & Movements & Origins & Destinations \\
\hline Retailers & 3 & 18,157 & 6 & 119 \\
\hline Manufacturers & 13 & 120,778 & 52 & 1,331 \\
\hline 3PLs & 2 & 21,418 & 63 & 363 \\
\hline TOTAL & 18 & $160,353^{*}$ & $113^{*}$ & $1,484^{*}$ \\
\hline
\end{tabular}




\subsection{Design of the case study investigation}

A case study approach was chosen as it is appropriate to describe and explore new phenomena or to build new theories (Eisenhardt 1989). A single longitudinal case study investigation was selected. The benefit of exploring a single case study is that more time can be invested in researching and understanding the investigated issue(s) over a wide period of time, especially if significant changes are undergoing (Strauss 1987). The study was based on data and information gathered by the authors during an in-depth case study within one of the working group's companies: Procter \& Gamble (P\&G). P\&G is a consumer product multinational that provides products in segments like beauty and grooming, health and wellbeing, and household care. The company believes that innovation can lead to an impact making every day better for people and the planet. Given the company's objectives of being competitive in the market from a cost and service viewpoint, along with a strong focus on conservation of resources and the use of renewable energies, $P \& G$ is directed towards the adoption of an L\&GSCM approach. Hence their interest in pursuing sustainable transport strategies. The company participated in a pilot implementation test (led by GS1 Italy IndicodECR) from July 2013 until April 2015, for the use of intermodal transport to deliver consumer goods along the Italian FMCG supply chain. The same time window reflected the duration of our field analysis.

The unit of analysis of the case was the organization of FMCG shipments among P\&G facilities and from P\&G facilities to customers (represented by retailers' distribution centres and stores), with respect to the Italian FMCG supply chain. Shipments are planned and managed centrally by a department called P\&G International Operations. 
With reference to data collection and analysis, a case study protocol was developed (Yin 2003). A data collection template was designed and gave the possibility of discussing the proposed questions and topics more freely. A draft was prepared and validated in order to check its completeness and clarity. The final version of the data collection template was used for leading the collection of data in our field analysis, and this approach was adopted to ensure consistency and completeness of information to achieve the aim of the research. The data collection template concerned three main areas: company information and sustainability targets; efforts and results obtained in the pilot implementation test; and challenges and enabling factors related to the modal shift. The director of Transportation Operations Western Europe Physical Distribution (to which the P\&G International Operations Department reports) and a Sustainability Research Fellow within the R\&D department were interviewed. Both of them had a primary role in defining the company's L\&GSCM strategy and in the deployment of the pilot test. Emerging themes and patterns were recorded in a case template (Miles and Huberman 1994). Transcriptions and other forms of documentation were assessed, i.e. the company's website, internal documents on the implementation of the project, and shipment databases. The authors took part in three workshops organized by GS1 Italy Indicod-ECR in which partial and final results were shared and discussed. This triangulation of data increased the reliability and validity of the results (Voss, Tsikriktsis and Frohlich 2002, Eisenhardt 1989). All the gathered field evidence was collated in a case study database. The produced case templates were shared with the interviewees for their validation. Discrepancies among different sources of information were resolved through a recalling of the interviewees.

\section{Results}

In this section we describe the results of our study, with reference to the application of the scenario-based estimation tool and to the insights arising from the P\&G case study. 


\subsection{Estimation of the potential demand for road-rail intermodal transport}

Figure 2 reports the results of the first scenario. The following parameter setting was adopted: radius of the catchment area of origin and destination hubs equal to $100 \mathrm{~km}$, minimum distance from origin to destination equal to $350 \mathrm{~km}$, and minimum lead-time equal to 1 day.

Parameters:

- $\mathrm{X}=\mathrm{Y}=100 \mathrm{~km}$

- LTmin = 1 day

- $\mathrm{Dmin}=350 \mathrm{~km}$

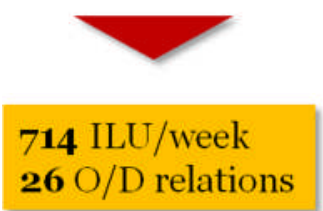

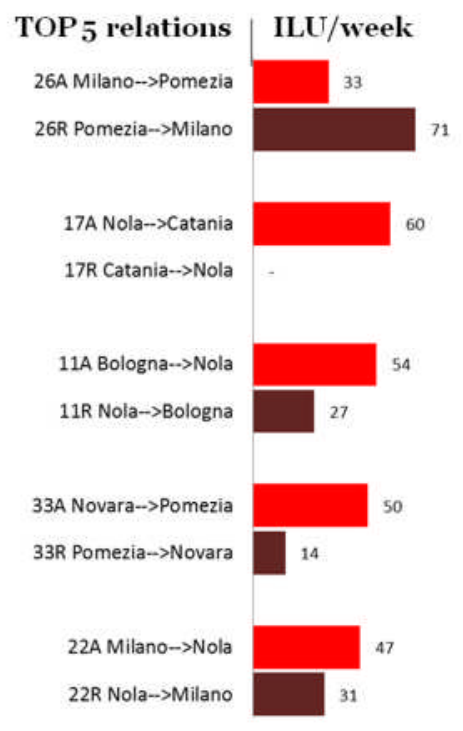

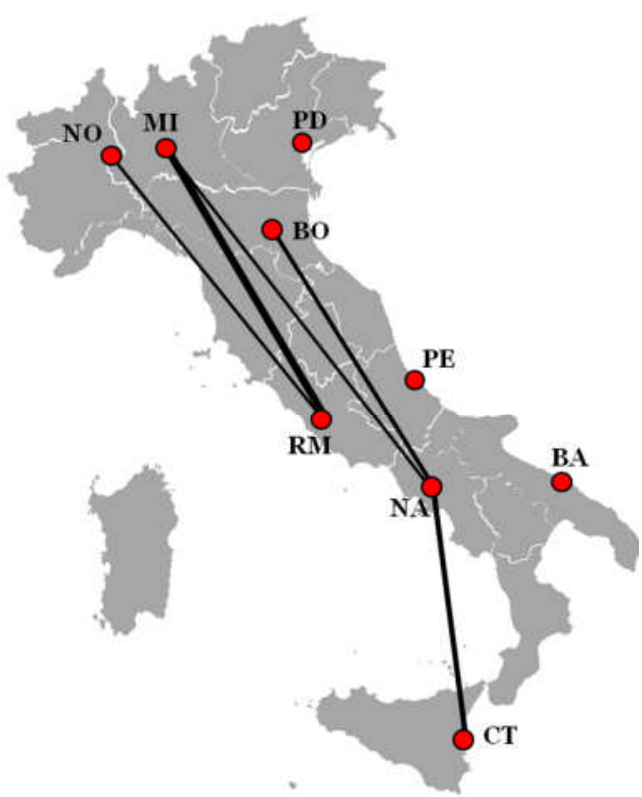

Figure 2 - The results of the first scenario

In this scenario, 714 ILU/week are obtained, corresponding to 35,000 ILU/year and to $22 \%$ of the overall freight movements included in the project database. The results highlight the importance of Bologna, Milano, and Novara as the main areas for Northern Italy and Catania, Nola, and Pomezia-Rome as the main areas for Central/Southern Italy. Figure 2 also shows a concentration of flows along the "Tyrrhenian Route" (i.e. the western coastal railway backbone) and the unbalance of logistics flows between Northern and Central/Southern Italy. A sensitivity analysis on the obtained results was performed. 
(a)

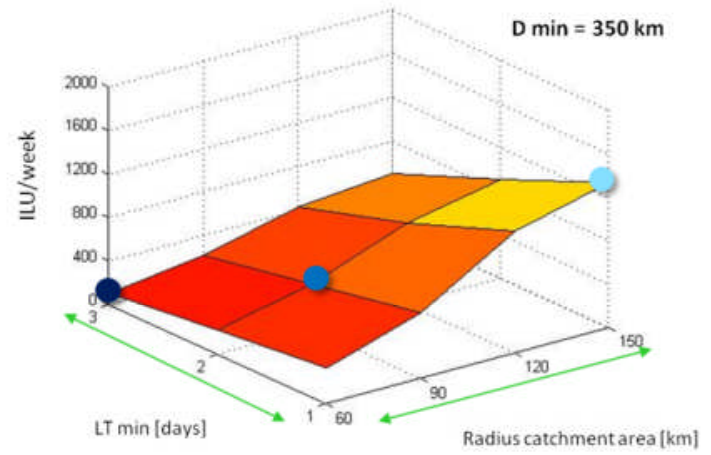

$110 \mathrm{ILU} /$ week, $(X=Y=60, \mathrm{LT}=3$ days $)$

$416 \mathrm{ILU} /$ week, $(X=\mathrm{Y}=90, \mathrm{LT}=2$ days $)$

1,330 ILU/week, $(X=Y=150, L T=1$ day $)$

(b)

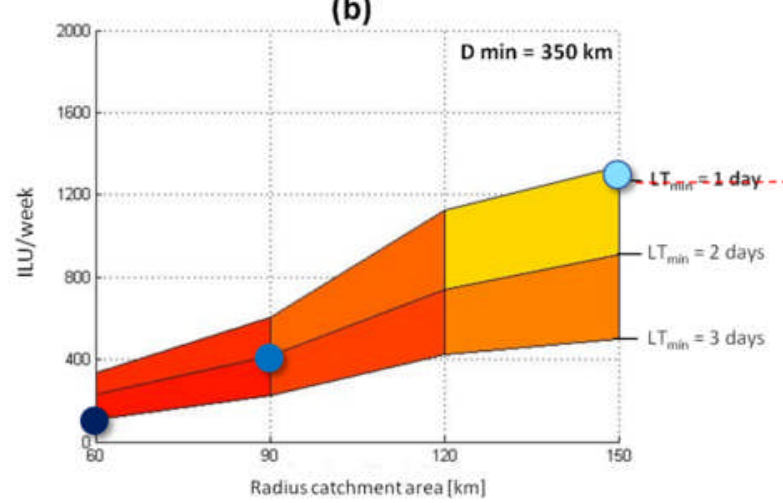

(c)

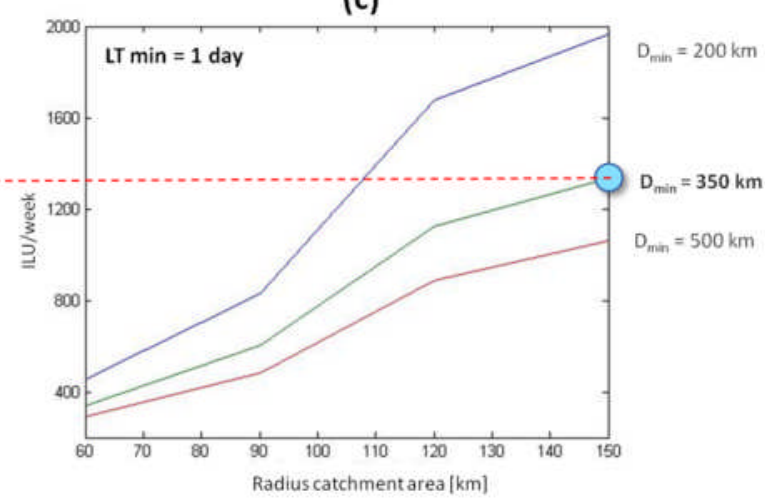

Figure 3 - The results of the sensitivity analysis

Figure 3(a) presents the results taking a fixed value of the minimum distance from origin to destination $(350 \mathrm{~km})$ and varying the minimum lead-time plus the radius of the catchment area of origin/destination areas. When constraints are particularly stringent (i.e. radius $=60 \mathrm{~km}$ and lead-time equal to 3 days), only $110 \mathrm{ILU} /$ week can be shifted from road to rail. With a relaxation of the constraints (i.e. radius $=150 \mathrm{~km}$ and lead-time equal to 1 day) 1,330 ILU/week can be shifted. Results shows that the number of ILUs potentially shifted is strongly dependent on these constraints. As shown in Figure 3(b), the relaxation of the leadtime constraint has a greater positive effect on the number of ILUs $<$ to potentially be shifted than the one obtainable by relaxing the constraint on the radius of the catchment area. Finally, Figure 3(c) depicts the effects of changes in the minimum distance from origin to destination, taking a fixed value of the minimum lead-time (i.e. 1 day). 
Figure 4 reports the results of the second scenario, taking a percentage split between the rail segment length and the overall travel distance equal/greater than $80 \%$ and a minimum lead-time equal to 1 day.

- LTmin $=1$ day

- $\mathrm{D}_{\mathrm{F}} /\left(\mathrm{D}_{\mathrm{F}}+\mathrm{x}+\mathrm{y}\right) \geq 80 \%$

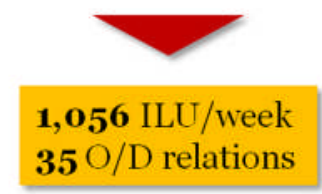

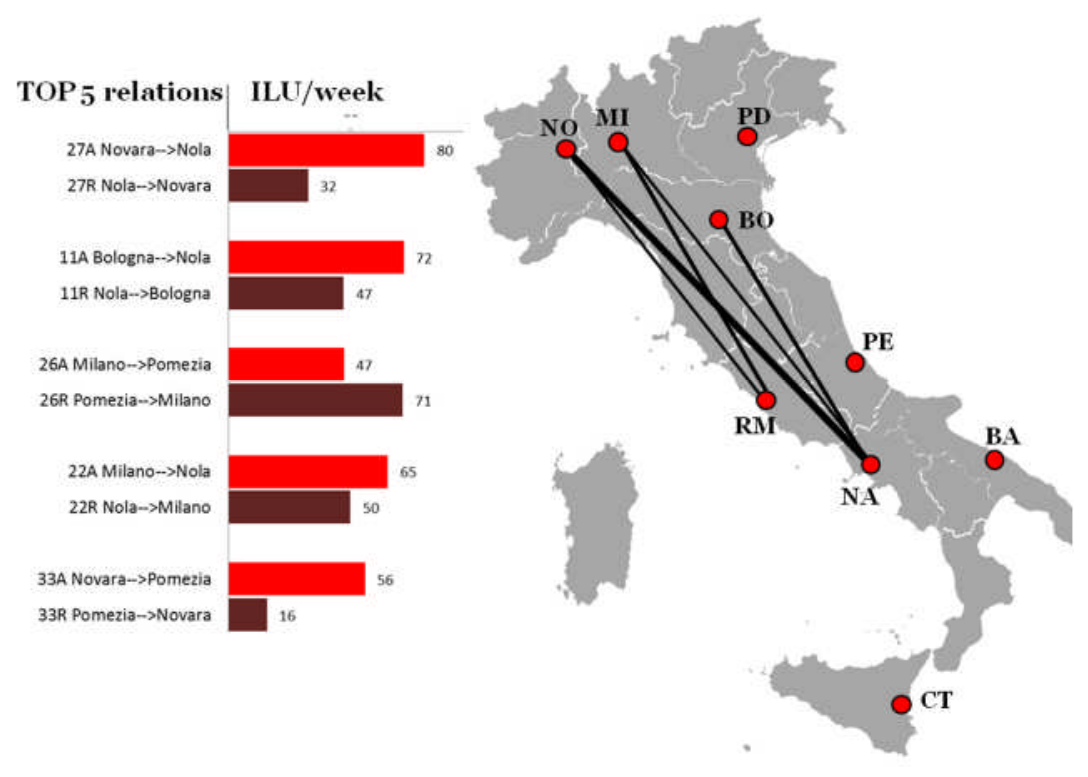

Figure 4 - The results of the second scenario

In this scenario, 1,056 ILU/week are obtained, corresponding to 52,800 ILU/year and to $33 \%$ of the overall freight movements included in the project database. The results confirm the importance of the main areas previously identified. Additionally, by having the constraint of the percentage split between the rail segment length and the overall travel distance set to $80 \%$, the shortest $\mathrm{O} / \mathrm{D}$ relations are disadvantaged, whereas the longest ones present a greater potential.

The results of the two presented scenarios show the existence of a potential demand for intermodal transport in the FMCG supply chain in Italy and identify a series of promising $\mathrm{O} / \mathrm{D}$ relations. The potential demand was derived from a database containing $10 \%$ of the overall Italian FMCG flows. Consequently, the overall actual demand for intermodal transport could be even greater. 
Results were judged relevant by the working group, as the following quote from one of the involved Manufacturers underlines:

"The study has showed that there are many opportunities that can be seized through a working group to gather together the different players in the FMCG supply chain from source to destination. We have the potentiality, but we need a change in our mind-set. We need to open ourselves, not to look just at what we have within the boundaries of our companies. We have to be daring and change our way of working."

This led GS1 Italy Indicod-ECR to organize a pilot implementation test of intermodal transport involving 15 companies operating in the Italian FMCG supply chain (including manufacturers, retailers, 3PLs, and multimodal transport operators - MTOs). The pilot test was intended to gather field evidence on the actual feasibility of the modal shift.

\subsection{From potentiality to reality: making the shift from road to rail feasible}

$\mathrm{P} \& \mathrm{G}$ took part in the pilot implementation test given their interest in enhancing the environmental sustainability of their operations. The company is pursuing the objective of increasing the use of intermodal transport for shipping FMCG products from the current $28 \%$ of the overall ton-km shipped to $30 \%$ by 2016 and $50 \%$ by 2020 .

\subsubsection{The pilot test for $P \& G$}

The pilot test was developed in three phases from July 2013 until April 2015. It was run with existing train services and without modifying the manufacturing/planning activities of the involved companies. With reference to $\mathrm{P} \& \mathrm{G}$, the test was run on one of the main $\mathrm{O} / \mathrm{D}$ relations for the company, i.e. Novara/Milano-Pomezia, one of the top relations identified in the estimation of the potential demand. The size of the origin catchment area was defined in agreement with the involved MTO to be equal to $10 \mathrm{~km}$, while at destination to be equal to $30-150 \mathrm{~km}$. The rail travelled distance was equal to approximately $600 \mathrm{~km}$. P\&G decided to 
run the test on "next day" orders (delivery within 24-48 hours without modifying the agreements on the delivery time windows with their customers) for non-perishable and nonfood products. 45-foot ILUs, i.e. swap bodies able to contain up to 33 palletized unit loads, were used for running the test. The operational "mechanism" of the test was composed of different steps. First, $P \& G$ ensured a high degree of visibility on the availability of the selected orders for the pilot test by sharing the information with the supply chain partners upstream and downstream. This was necessary to facilitate the organization of the intermodal delivery process and to allow for greater coordination - something that, according to the interviewees, is not very common in the FMCG supply chain. Basing on the received information, the MTO had the possibility to book the appropriate train service(s) and make the ILU(s) available at P\&G's manufacturing plant docks. Thanks to the sharing of information, the MTO was able to monitor in real time the entire process. In case of delays in the load preparation, which could lead to the impossibility to meet the scheduled train appointment, the MTO was enabled to free the booked service and make this freed transport capacity available for other customers. In organizing the door-to-door delivery service, the MTO ensured that in case of matters arising with reference to the intermodal transport, an allroad transport backup could be activated for completing the planned delivery. The real-time information regarding the delivery process and status was shared with the customer(s) (i.e. the consignee), and the transport schedule was agreed between $P \& G$ and the customer based on the existing delivery time windows.

To evaluate the pilot test, the company analysed the encountered problems in the modal shift and the causes generating those issues.

Additionally, a dashboard of Key Performance Indicators (KPIs) was defined, in terms of efficiency, effectiveness, and sustainability of the intermodal transport: 
- Average difference between the all-road delivery cost and the road-rail intermodal transport delivery cost [€/ILU];

- On-Time-Delivery (OTD) defined as the percentage of deliveries completed within the agreed time window [\%];

- Average $\mathrm{CO} 2$ emissions percentage difference between the all-road delivery and the road-rail intermodal transport delivery [\%].

\subsubsection{The results of the pilot test}

1,625 customer loads were concerned over the three phases. These loads account for approximately $20 \%$ of the total Full Truck Load Shipments organized by P\&G on the O/D relation Novara/Milano - Pomezia, and they represent the potential flows to be shifted from road to rail. The test involved 189 customers located across 32 Italian provinces.

Out of the concerned loads, $17 \%$ were actually shifted from road to rail. Four main categories of causes of the misalignment between the overall potentially shifted flows and the actually shifted ones were identified:

- Missed loads due to P\&G: this category is related to issues in the planning of shipments due to manufacturing delays internal to $P \& G$. This accounts for $14 \%$ of the potential flows. For running the pilot test, no amendments to the current production planning were introduced. This resulted in a series of missed loads on trains due to variations in the production schedule in $P \& G$ 's planning process. The company, in fact, for reasons including rush orders and late production due to backlogs, needed to alter the pre-determined shipment schedule. These changes in the upstream supply chain could be accommodated by the all-road transport but not by the intermodal transport due to train schedules/operational constraints. 
- Missed loads due to order size: this category exists because the customer order size can be non-compatible with the loading capacity of the adopted ILUs. This accounts for $19 \%$ of the potential flows. In those cases data show that customers placed orders, which size was equal to 34 pallets. This exceeded the capacity of the adopted ILUs (33 pallets). In those cases $P \& G$ was forced to rely on all-road deliveries for accommodating customers' requests.

- Missed loads due to train causes: this category refers to cancellations, unavailability of a train service, or assets and to insufficient loading capacity. This accounts for $9 \%$ of the potential flows. These problems emerged since the pilot test was run relying on the existing offer of train services (no ad-hoc services were introduced). When it wasn't possible to guarantee balanced flows on both directions connecting the origin and destination hubs, the MTO was forced to cancel the train service due to insufficient demand. $P \& G$ lamented also that in some cases the missed loads were due to waiting times for obtaining an empty ILU for loading goods and to unavailable flatbed trailers for completing the drayage operations.

- Missed loads due to non-compatible delivery time windows: this category refers to the misalignment between the agreed delivery time windows with customers and the delivery time deriving from the adoption of intermodal transport. This accounts for $41 \%$ of the potential flows. Due to the existing train schedules and terminal operations times, by adopting the intermodal transport it would have been impossible for $\mathrm{P} \& \mathrm{G}$ to meet the delivery times requested by customers. For better alignment between the intermodal transport times and the customers' delivery time windows, $\mathrm{P} \& \mathrm{G}$ rescheduled for two hours earlier the train loading activities. By making the loads available on the train earlier it was also possible to stretch the catchment area of the 
destination hub and reach customers located up to $150 \mathrm{~km}$ from the hub (when compatible time windows applied).

The KPI dashboard reported the following results:

- Average difference between the all-road delivery cost and the road-rail intermodal transport delivery cost $[€ / \mathrm{ILU}]=50 € / \mathrm{ILU}$;

- On-Time-Delivery (OTD) defined as the percentage of deliveries completed within the agreed time window $[\%]=96 \%$, against $98 \%$ for the all-road option;

- Average $\mathrm{CO} 2$ emissions percentage difference between the all-road delivery option and the road-rail intermodal transport delivery option $[\%]=30 \%$.

\subsubsection{Discussions}

The results of the test in terms of loads actually shifted from road to rail seem to confirm the existence of a potential demand for intermodal transport. The same can be said for the feasibility of the modal shift, even with the current availability of intermodal services, supply chain planning processes, and companies' operations.

Results confirm the opportunities to increase the sustainability and efficiency of the supply chain, in line with the extant literature that stresses the opportunities to concurrently reduce $\mathrm{CO} 2$ emissions and optimise transportation costs (Colicchia et al. 2016, Garza-Reyes et al. 2016). However, intermodal transport documented a slight decrease in effectiveness.

The discussion of the field evidence with the interviewees allowed identifying six groups of factors enabling an increased use of intermodal transport together with better performance in terms of effectiveness, efficiency, and sustainability. In the discussion we also engaged with the literature, and this helped in producing recommendations (Table 2). 
Table 2 - Enabling factors for the modal shift

ENABLING FACTOR CURRENT SITUATION

Rigid Order to Delivery Cycle in the FMCG sector

Order size decisions taken regardless intermodal transport constraints

Planning and Managemen

Variable and unbalanced bi-directional flows on $\mathrm{O} / \mathrm{D}$ relation

Limited visibility on the logistics flows across the supply chain

Limited compatibility of intermodal transport

systems and operations with the FMCG flows

Assets

Limited availability of ILUs and flatbed trailers

Limited availability of train services

Train services

Constrained train schedules

Unclear rules for cost and profit sharing along the chain of supply

Decisions taken in isolation

Collaboration rules not specified

Poor committment

Limited availability of intermodal-specific

contractual agreements

Limited funding available for start-up

intermodal initiatives

Incentive Schemes within the company and along the supply chain

\section{IDEAL SITUATION}

Shared overlap of the replenishment mechanisms in the supply chain and in transport operations

Diffused alignment of order size decisions with intermodal transport constraints

Critical mass of flows with balanced bi-directiona flows on $\mathrm{O} / \mathrm{D}$ relations

Diffused visibility on the logistics flows across the supply chain

High quality and reliability of the intermodal operations

Wide availability of ILUs and flatbed trailers

HOW TO GET THERE?

Agility and flexibility approaches in the production and replenishment planning

Raise awarness of intermodal transport constraints among supply chain partners

Centralized planning within the company and collaboration in the supply chain with an integrator

Trust, synchronized IT systems

Development of quality assurance procedures and communications with shippers

Creation of asset sharing and return schemes, tracking and capacity management

Matching supply and demand for intermodal

Wide availability of dedicated freight train services transport to support the introduction of new services, small scale trial

Matching supply and demand for intermodal transport to support flexibility of train services, small scale trial, path flexibility

Well defined rules for cost and profit sharing along Industry initiatives in collaboration with academic the chain of supply community, government and trade associations

Decisions shared with supply chain partners

Horizontal and vertical collaboration

Clear collaboration rules

"Code of conduct" for collaboration

Widespread appraisal of L\&GSCM approach

Champions at senior level, changed mindset

Standardised and accepted contracts for activating intermodal transport services

Industry initiatives in collaboration with academic community and trade associations

Availability of funding schemes for virtuous applications

Targeted funding from EU or national governments

Fair EU and national regulations (e.g. taxation on road transport) 


\subsubsection{Planning and Management}

The first factor to be mentioned is the Order to Delivery Cycle. With the current operating conditions in the FMCG sector the target service level cannot always be achieved with intermodal transport. Shared replenishment mechanisms in the supply chain and in transport operations through increased agility and flexibility (including agreements on delivery time windows) would be beneficial to decreasing the number of missed shift opportunities, as pointed out by the interviewees and in line with the literature (Villareal, Garza-Reyes and Kumar 2016, Rodemann and Templar 2014).

"Manufacturers and retailers should collaborate more extensively, along with transport operators, for allowing more flexibility for the collection and delivery of products over the 24 hours of the day."

The replenishment mechanisms should also embrace order size decisions aligned with intermodal transport constraints to be achieved through an increased communication among supply chain partners (especially between customers and shippers), as clearly shown in the pilot test and hypothesized in the literature (Monios 2015). The feasibility of the modal shift is also connected to the existence of a critical mass of flows along the chain of supply (Ballot and Fontane 2010, Groothedde, Ruijgrok and Tavasszy 2005). From a single company's perspective, this is crucial, especially when flows are strongly variable over time and affected by reorders and promotional plans not directly controlled by supply chain managers.

"The main problem is the variability of the flows, which is caused internally by our promotional plans and downstream by the reorder plans of retailers. It looks like logistics is affected by sales processes.”

The critical mass could be achieved through an aggregation of flows enabled by a centralized planning within the single company and by horizontal and vertical collaboration along the supply chain, as advocated by Mason, Lalwani and Boughton (2007). The consolidation of flows and the compensation of the variability of the demand for transport 
over time could be centrally and dynamically managed by an integrator acting as a control tower (Pan, Ballot and Fontane 2013, Lammgard 2012). This, as suggested by the company, could be potentially achieved through an independent fourth-party logistics provider that is able to combine the interests of supply chain players.

"Horizontal collaboration among companies is possible but very complicated to achieve in practice. An integrator is needed, in other words an external player that works on making the collaboration possible and able to facilitate the optimization of the system."

An additional factor emerging from the pilot test and from the literature is represented by a diffused visibility on the flows across the supply chain in terms of cost allocation and real-time tracking of flows for better service reliability (Macharis et al. 2012). This can be achieved through synchronized information systems for sharing data among supply chain partners as promoted by $\mathrm{P} \& \mathrm{G}$ in the pilot test.

“A reliable real-time data repository with enough guarantees of security and confidentiality is a true aggregating factor in terms of relationships within the collaboration initiative."

The literature supports this view, as information systems play a critical role for increasing the flow of data, for improving the quality of information, and for offering the possibility to control and coordinate operations in real-time (Caris, Macharis and Janssens 2013).

\subsubsection{Assets}

The possibility of actually shifting loads from road to rail is often constrained by the inability of intermodal terminals and ILUs to accommodate the necessities of the FMCG supply chain and by the lack of optimal asset utilization. The literature stresses the relevance of having intermodal terminal operations adapting more flexibly to the necessities of shippers and transport operators: this includes opening times of terminals spanning on wider time 
windows and on more days of the week, along with reasonable additional costs for operations carried out in "extra-time" conditions (to be paid by the user - e.g. avoiding to pay double on Sundays) (Monios 2015). Operational issues related to the opening times of terminals were also highlighted by the company.

"There is a problem with the opening times of intermodal terminals. It would be necessary to have also rail services for allowing loading/unloading operations during the night."

Better quality assurance procedures and communication with shippers on the operational conditions of terminals and assets would be beneficial to improve the quality/reliability of intermodal operations (Villarreal, Garza-Reyes and Kumar 2016, EngLarsson and Kohn 2012). As it emerged from the pilot test asset tracking, sharing, and return schemes (with specific reference to empty flatbed trailers and ILUs) would allow for a better capacity management. This would even allow for the use of the same assets for products characterized by different requirements, thus increasing the possibility to balance the return flows of trains.

"On an O/D relation, the same reefer ILUs used on one direction can be used as nonreefer ILUs on the other one if necessary: this is a solution for better managing assets capacity but it is rarely implemented in reality."

In the literature this has been studied as a resource management problem that tackles the allocation of resources in the intermodal transport network. As stressed by the company, this is critical for the well-known limited availability of assets, including ILUs and flatbed trailers. Resource management encompasses empty loading unit repositioning, which seeks to dynamically optimize the allocation of empty ILUs where they're needed after a delivery service is completed. This would allow re-balancing the availability of assets in the intermodal transport network and to match more accurately the demand and supply of 
transport services. Such action is intended to make sure that after a resource is released, it would be repositioned where it is needed. To achieve this objective, the literature acknowledges the importance of incorporating backward flows into transportation planning and resource management (SteadieSeifi et al. 2014).

\subsubsection{Train services}

This category refers to the availability of a sufficient number and spread over time of train services to meet the demand for intermodal transport. This could also guarantee the service level performance required by the FMCG supply chain, as the interviewees pointed out.

"It is hoped that this successful pilot test starts a virtuous circle: from a situation in which only the existing train services can be used, to a situation where the aggregated flows facilitate and justify the introduction of new, suitably scheduled and more reliable train services. This would make possible to achieve the required service level with intermodal transport."

A critical mass of flows needs to be realized through small scale trials that will enable supply chain players to connect and match supply and demand, justifying the introduction of new train services (Lammgard 2012). The pilot test described in this paper represents a first attempt to disseminate insights on the actual feasibility of the modal shift to facilitate the development of new train services. Other avenues for obtaining a wider selection of available train services could focus on enhancing the path flexibility of the existing network, as suggested by the literature (Monios 2015): releasing unused or underused tracks that would become available to other transport operators could help in improving the general flexibility and responsiveness of rail services. This flexibility could also be enhanced through relaxation of path restrictions that give priority to passenger transport during the day, and force freight trains to run only during the night (notwithstanding the average higher cost for the night shifts 
of train drivers). As our interviewees pointed this could be beneficial for aligning train schedules to the flexibility necessities of the FMCG supply chain operations but it could become difficult to realise when paths during the day are already busy.

\subsubsection{Supply Chain Collaboration}

The study demonstrated that wider issues related to collaboration initiatives in the supply chain exist. The interviewees pointed out that it would be beneficial to have a clear understanding of the rules regulating the "profit and cost" sharing among the different players, as confirmed by the literature (Zhou, Van Hui and Liang 2011).

"A first essential point is the definition of cost allocation rules among players in the relationship: this would smooth the way for starting and keeping alive the collaboration initiative”.

This is a recent matter of study (see for example the European Project CO3 Collaboration Concepts for Co-modality carried out between 2012 and 2014). To support the introduction of collaboration initiatives, it would be necessary to foster the development of working groups and experimentations linking together practitioners, academics, and facilitators, such as trade associations and governmental bodies. This would help in overcoming the limitations of the traditional decision making process in the FMCG supply chain, where players take decisions in isolation. Horizontal/vertical collaboration is advocated to foster decisions shared with supply chain partners (Mason, Lalwani and Boughton 2007). The interviewees claimed that it would be necessary to define clear collaboration rules, at the moment non-existing, in a "code of conduct". These rules should determine the mechanisms for joining/leaving the collaboration initiative and facilitate a collaborative use of intermodal transport by leveraging spare capacity across the network (Vachon and Klassen 2006). 
"If a clear definition of joining mechanisms together with mechanisms for leaving the collaboration initiative existed, I would expect more and more companies to be interested in joining."

This would represent the foundations for establishing trust in the relationships across the supply chains partners, which is a key element for enabling supply chain collaboration, as underlined by the literature (Ballot and Fontane 2010). Additionally, one of the foremost drivers of the success of collaboration initiatives, as strongly claimed by the interviewees, is represented by the widespread appraisal of the importance of the L\&GSCM approach among supply chain players (Garza-Reyes 2015, Rossi et al. 2013).

L\&GSCM principles should be embedded in companies' strategy through champions at senior level and a changed mind-set in organizations to lead the development of a lean and green FMCG supply chain. According to the interviewees, this seems to be far from a reality in the current situation, as also supported by the literature (Monios 2015, Abbasi and Nilsson 2012).

"A change in the mind-set of the people working in the FMCG supply chain is not an option; it is a necessity and a challenge that cannot be neglected. Not all companies recognise the importance of environmental sustainability - we need to spread the voice and educate professionals."

\subsubsection{Legal issues}

Given the complexity of the involved relationships, intermodal transport is different from unimodal transport, and it requires specific contracts that are true enablers of coordination among companies (Eng-Larsson and Norrman 2014). This is especially critical in environments, such as the FMCG supply chain, where supply chain collaboration is essential to drive the modal shift. 
"The feasibility of the modal shift is also affected by how formal relationships and contractual agreements are managed from a legal perspective: as a company you don't want to commit to anything if you feel that you are constraining yourself to something you don't feel comfortable with and protected."

Consequently, according to the interviewees, contractual agreements should include rules for sharing/pooling the risks connected to the uncertainty and volatility of demand for transport services. Likewise, in the relationship the perspective of both parties and not only the perspective of the "strongest" player should be taken when contracts are designed. This is also reflected in the literature, where it is suggested that contracts for intermodal services should reflect the reciprocity of the buyer-supplier relationship and focus on the contracting dynamics (Eng-Larsson and Kohn, 2014). Further to this, the interviewees underlined the necessity of industry initiatives in collaboration with the academic community and trade associations. Building on research on supply chain/transport contracting, these initiatives should define the legal mechanisms binding the players in terms of transaction flows, allocation of demand, and capacity risk in the modal shift. Also environmental aspects should be encompassed in the guidelines for designing comprehensive and contemporary contractual agreements, in line with the literature (Eng-Larsson and Kohn, 2014).

\subsubsection{Incentive schemes}

A strong commitment from the public sector must be conducive to the growth of intermodal transport (Beskovnik and Twrdy 2015). Since the start-up of modal shift initiatives requires initial investments and can imply extra costs in the ramp-up stage, as described by the interviewees, targeted funding from the European Union and national governments would be beneficial to support developments (Monios 2015). 
"Public funding and support are necessary especially in the start-up phase of an initiative, rather than when the initiative is up and running. The initial barriers are too high for single players to commit."

"External pressures" could be introduced as a disincentive for maintaining traditional all-road based processes/deliveries, which, as demonstrated by the P\&G case study, are not necessarily a source of benefits. Measures such as taxation and restrictions on road transport are being introduced in some European countries, but this is still being investigated (Gutierrez et al. 2013). Along these lines, the interviewees pointed out that companies unengaged with green initiatives could be penalized:

"It would be opportune to introduce more onerous taxes for those companies that do not undertake measures aimed at limiting $\mathrm{CO}_{2}$ emissions."

On the other hand, incentive mechanisms, such as the reduction of fees to operate on the intermodal infrastructure, could be beneficial for the growth of the modal shift, as advocated by the literature (Eng-Larsson and Norrman 2014).

Financial frameworks and regulatory actions such as incentives/disincentives could be enabler of the modal shift for greater use of intermodal transport, and these schemes could lead all together to the development and operation of real hub terminals, as indicated by the literature (Kreutzberger and Konings, 2016).

\subsubsection{A collaborative business model for making the modal shift possible}

It was possible to conceive a collaborative business model for facilitating the modal shift from road to rail. GS1 Italy built on the outcomes of the CO3 European Project to define the contractual and operational agreements among the parties involved, i.e. shippers, logistics service providers, and MTOs. The lesson learned from the evidence is that collaboration hardly happens since trust among players is generally lacking along with rules for fair competition/interactions. In the proposed collaborative business model, a new player is 
introduced: the trustee, i.e. an individual or an organization acting as neutral and transparent collector of information related to the shippers' freight movements. The trustee communicates also with logistics service providers and MTOs for transport capacity management and operations execution. It creates the critical mass necessary to connect the supply and demand for intermodal transport. These activities need to be supported by adequate IT systems and visibility/tracking software packages. Taking the responsibility of legal contracts among the parties, the trustee ensures data protection and confidentiality so that fair competition among shippers is guaranteed. Supply chain collaboration is hence enabled by a "manifesto for collaboration" published by the trustee and subscribed by the shippers, logistics service providers, and MTOs.

An extension of this collaborative business model is represented by the involvement of consignees (e.g. retailers) to adopt a true end-to-end supply chain perspective. This can be done by raising awareness of intermodal transport opportunities among consignees to better align their planning with the replenishments in the entire supply chain. It would be advisable to leverage the role of the trustee to engage with consignees through appropriate agreements and create a vertical and horizontal collaboration.

\section{Conclusions}

The present research investigated how companies can adopt an L\&GSCM approach through intermodal transport to be efficient, effective, and sustainable in today's competitive arena.

We have provided an answer to our research question (i.e. how is it possible to make the modal shift from road to rail actually feasible by connecting the supply and demand of intermodal transport along the supply chain?) by proposing a scenario-based estimation tool of the potential demand for intermodal transport and by discussing a real-life case study of adoption of intermodal transport in the Italian FMCG supply chain. 
The estimation of the potential demand represents a starting point to achieve a stepchange in transport efficiency, effectiveness, and sustainability whose feasibility, however, depends on a number of factors, as discussed in the case study. Our study has identified a number of pathways for action from both a theoretical and practical perspective.

From a theoretical perspective, this research is the first in the academic community to address the adoption of intermodal transport from a supply chain perspective, providing a holistic view that feeds into a newly developed business model. In this way, this paper contributes to the theories on the actual feasibility of the modal shift from road to rail. The proposed scenario-based estimation tool represents an instrument that could be easily adopted in other contexts including appropriate input data and values of parameters. We have provided the academic community with field evidence that complements the current availability of theoretical studies, mostly proposing illustrative quantitative models.

From a practical perspective, our research offers companies insights on the challenges and opportunities of shifting from road to rail, through the discussion of a case study and an end-to-end supply chain collaborative business model. This study contributes to the development of best practices, which might help in breaking the "vicious circle" of the misalignment between supply and demand that keeps intermodal transport at low levels of quality and prevents from beneficial investments from operators and public bodies.

In fact, the implications of our work regard also policy. While an effort should come from organizations in the FMCG supply chain as previously discussed, public bodies and policy makers should act as a catalyst for empowering supply chains in the modal shift. As discussed in this paper, tools for making this possible are represented by targeted funding (National and EU) for starting the initiatives and disincentives for less green modal choices. From the policy making viewpoint, additional avenues for making the modal shift a reality can be represented by "federated or centralised approaches" to hub planning and load 
bundling or consolidation with the aim to enable critical mass in rail transport. Our study, in fact, highlighted the potential to create this critical mass thanks to the aggregation of freight movements through collaborative approaches in the end-to-end supply chain. These approaches could also enable a wider collaboration between intermodal corridors, fostering the adoption of a "network vision" that can allow for maximising trainloads instead of minimising travelling distances, as also supported by the literature (Kreutzberger and Konings, 2016).

The main limitation of this study is that the discussion is based on the experience of a single company operating in a specific sector, although within a wider group of companies that shared the outcomes of the pilot test and provided the data regarding the potential demand for intermodal transport. It should also be recognized that our work focused on the FMCG supply chain with the roll-out of the pilot test in Italy: however the discussion of the enabling factors are not strictly related to the Italian context as they address challenges and opportunities that are typical to intermodal transport in general. For example the realisation of the critical mass to ensure efficient and timely service is common to the organization of intermodal services in any country. Consequently, it is believed that the present study offers meaningful directions for well-grounded initiatives towards a step-change in the growth of intermodal transport. The results of our work can also stimulate further research to provide new empirical evidence, e.g. by extending this study to the European area to further investigate the enabling factors of intermodal transport at an international level and in other industries. Other pilot tests should encompass also the adoption of the discussed business model. Future research should focus on refining the content of the agreements and the management of the collaborative relationships among supply chain partners. 


\section{Acknowledgements}

The authors would like to thank P\&G, GS1 Italy Indicod-ECR and the companies participating in the working group.

\section{References}

Abbasi, M. and F. Nilsson. 2012. "Themes and challenges in making supply chains environmentally sustainable.” Supply Chain Management: An International Journal 17 (5): 517-530.

Anten, N., W. Ploos van Amstel, and K. Verweij. 2014. "Lean and Green: creating a network community for sustainable logistics." Transport Research Arena 5th Conference: Transport Solutions from Research to Deployment, 2014.

Ballot, E. and F. Fontane. 2010). "Reducing transportation CO2 emissions through pooling of supply networks: perspectives from a case study in French retail chains." Production Planning \& Control: the Management of Operations 21 (6): 640-650.

Beškovnik, B. and E. Twrdy. 2012. "Green logistics strategy for South East Europe: to improve intermodality and establish green transport corridors." Transport 27 (1): 2533.

Bhattacharya, A., S.A. Kumar, M. Tiwari, and S. Talluri. 2014. "An intermodal freight transport system for optimal supply chain logistics." Transportation Research Part C: Emerging Technologies 38 (1): 73-84.

Blome, C., A. Paulraj, and K. Schuetz. 2014. "Supply chain collaboration and sustainability: a profile deviation analysis." International Journal of Operations \& Production Management 34 (5): 639 - 663.

Bourlakis, M.A., and P.W.H. Weightman. 2004. Food Supply Chain Management, Blackwell Publishing, Ames, Iowa USA, 1st ed.

Caris, A., C. Macharis, and G.K. Janssens. 2013. "Decision support in intermodal transport: A new research agenda." Computers in Industry 64 (2): 105-112.

Cheng, T.C.E., K. Lai, Y.H.V. Lun, and C.W.Y. Wong. 2013. "Green shipping management." Transportation Research Part E: Logistics and Transportation Review 55 (1): 1-2.

Colicchia, C., A. Creazza, F. Dallari, and M. Melacini. 2016. "Eco-efficient supply chain networks: development of a design framework and application to a real case study." Production Planning \& Control: the Management of Operations 27 (3): 157-168. 
Dallari, F., G. Marchet, L. Lanini, C. Colicchia, and S. Perotti. 2015. La Logistica per la creazione di valore nella filiera del largo consumo. ECR Italy Bluebook (available at: https://gs 1it.org/content/public/46/e6/46e65baf-6bbf-4a01-a304929a7d6899b3/logistica_creazione_valore_filiera.pdf)

De Langen, P.W., and M. R. Van Der Horst. 2008. "Coordination in Hinterland Transport Chains: A Major Challenge for the Seaport Community." Maritime Economics \& Logistics 10 (1-2): 108-129.

Eisenhardt, K. M. 1989. "Building theories from case study research.” Academy of Management Review 14 (4): 532-550.

Eng-Larsson, F. and C. Kohn. 2012. "Modal shift for greener logistics - the shipper's perspective.” International Journal of Physical Distribution \& Logistics Management 42 (1): 36-59.

Eng-Larsson, F. and A. Norrman. 2014. "Modal shift for greener logistics - exploring the role of the contract." International Journal of Physical Distribution \& Logistics Management 44 (10): 721-743.

Escudero, A., J. Muñuzuri, J. Guadix, and C. Arango. 2013. "Dynamic approach to solve the daily drayage problem with transit time uncertainty." Computers in Industry 64 (2): $165-175$.

Fernie, J. and L. Sparks. 2014. Logistics and Retail Management: Emerging Issues and New Challenges in the Retail Supply Chain, Kogan Page, London, 4th ed.

Fernie, J., L. Sparks, and A.C. McKinnon. 2010. "Retail logistics in the UK: past, present and future.” International Journal of Retail \& Distribution Management 38 (11-12): 894914.

Fornari, E., D. Fornari, S. Grandi, and M. Menegatti. 2013. "The influence of retailing-mix levers on private label market share: the case of the Italian FMCG market." Journal of Retailing and Consumer Services 20 (4): 617-624.

Freight Leaders Council. 2016. La Sostenibilità nei Trasporti e nella Logistica. Quaderno 25 (available at: http://www.freightleaders.org/i-quaderni/)

Garza-Reyes, J.A., B. Villarreal, V. Kumar, and P. Molina Ruiz. 2016. "Lean and green in the transport and logistics sector - a case study of simultaneous deployment." Production Planning \& Control: the Management of Operations DOI:10.1080/09537287.2016.1197436

Garza-Reyes, J.A. 2015. "Lean and green - a systematic review of the state of the art literature." Journal of Cleaner Production 102 (1): pp. 18-29. 
Ghiani, G., G. Laporte, and R. Musmanno. 2013. Introduction to logistics systems management, Wiley, John \& Sons, Oxford, 2nd ed.

Groothedde, B., C. Ruijgrok, and L. Tavasszy. 2005. “Towards collaborative, intermodal hub networks." Transportation Research Part E: Logistics and Transportation Review 41 (6): 567-583.

Gutiérrez, J., A.M. Condeço-Melhorado, J.C. Martín, and C. Román. 2013. "Road pricing in the European Union: direct revenue transfer between countries." Journal of Transport Geography 33 (1): 95-104.

Iannone, F. 2012. "A model optimizing the port-hinterland logistics of containers: The case of the Campania region in Southern Italy." Maritime Economics \& Logistics 14 (1): 3372.

Jaegler, A., and P. Burlat. 2012. "Carbon friendly supply chains: a simulation study of different scenarios." Production Planning \& Control: the Management of Operations 23 (4): 269-278.

Kreutzberger, E.D., and R. Konings. 2016. "The challenge of appropriate hub terminal and hub-and-spoke network development for seaports and intermodal rail transport in Europe." Research in Transportation Business \& Management 19 (6): 83-96.

Kreutzberger, E.D. 2008. "Distance and time in intermodal goods transport networks in Europe: A generic approach." Transportation Research Part A: Policy and Practice 42 (7): 973-993.

Lammgård, C. 2012. "Intermodal train services: A business challenge and a measure for decarbonisation for logistics service providers." Research in Transportation Business \& Management 5: 48-56.

Macharis, C., L. Vanhaverbeke, T. van Lier, E. Pekin, and D. Meers. 2012. “Bringing intermodal transport to the potential customers: An interactive modal shift website tool." Research in Transportation Business \& Management 5: 67-77.

Maes, J., and T. Vanelslander. 2011. "The use of rail transport as part of the supply chain in an urban logistics context." In City Distribution and Urban Freight Transport: Multiple Perspectives, edited by Macharis C. and S. Melo, 217-233. Cheltenham: Edward Elgar.

Mangan, J., C. Lalwani, and B. Gardner. 2004. "Combining quantitative and qualitative methodologies in logistics research." International Journal of Physical Distribution and Logistics Management 34 (7): 565-578. 
Martínez-Jurado, P.J., and J. Moyano-Fuentes. 2014. "Lean Management, Supply Chain Management and Sustainability: A Literature Review." Journal of Cleaner Production 85: $134-150$.

Mason, R., C. Lalwani, and R. Boughton. 2007. "Combining vertical and horizontal collaboration for transport optimisation." Supply Chain Management: An International Journal 12 (3): 187-199.

Meisel, F., T. Kirschstein, and C. Bierwirth. 2013. "Integrated production and intermodal transportation planning in large scale production-distribution-networks." Transportation Research Part E: Logistics and Transportation Review 60: 62-78.

Miles, M.B., and A.M. Huberman. 1994. Qualitative Data Analysis: An Expanded Sourcebook. Beverly Hills. CA: Sage.

Monios, J. 2015. "Integrating intermodal transport with logistics: a case study of the UK retail sector." Transportation Planning and Technology 38 (3): 347-374.

Monios, J., and R. Bergqvist. 2015. "Operational constraints on effective governance of intermodal transport." Research in Transportation Business \& Management 14: 1-3.

Morgan, D. L. 1988. Focus Groups as Qualitative Research. Beverly Hills. CA: Sage.

Nielsen. 2016. Nielsen Growth Reporter Q2 2016. Available at: http://www.nielsen.com/uk/en/press-room/2016/Nielsen-growth-reporter-Q22016.html

Pan, S., E. Ballot, and F. Fontane. 2013. "The reduction of greenhouse gas emissions from freight transport by pooling supply chains." International Journal of Production Economics 143 (1): 86-94.

Piercy, N., and N. Rich. 2015. "The relationship between lean operations and sustainable operations." International Journal of Operations \& Production Management 35 (2): $282-315$.

Rodemann, H., and S. Templar. 2014. "The enablers and inhibitors of intermodal rail freight between Asia and Europe.” Journal of Rail Transport Planning \& Management 4 (3): 70-86.

Rossi, S., C. Colicchia, A. Cozzolino, and M. Christopher. 2013. "The logistics service providers in eco-efficiency innovation: an empirical study." Supply Chain Management: An International Journal 18 (6): 583-603.

SteadieSeifi, M., N.P. Dellaert, W. Nuijten, T. Van Woensel, and R. Raoufi. 2014. "Multimodal freight transportation planning: A literature review." European Journal of Operational Research 233 (1): 1-15. 
Strauss, S. 1987. Qualitative Analysis for Social Scientists. Cambridge University Press. New York. NY.

Vachon, S. and R.D. Klassen. 2006. "Extending green practices across the supply chain." International Journal of Operations \& Production Management 26 (7): 795 - 821.

Villarreal, B., J. A. Garza-Reyes, and V. Kumar. 2016. "Lean road transportation - a systematic method for the improvement of road transport operations." Production Planning \& Control: the Management of Operations doi: 10.1080/09537287.2016.1152405.

Voss, C., N. Tsikriktsis, and M. Frohlich. 2002. "Case research in operations management." International Journal of Operations \& Production Management 22 (2): 195-219.

Woodburn, A.G. 2006. “The non-bulk market for rail freight in Great Britain.” Journal of Transport Geography 14 (4): 299-308.

Yin, R. K. 2003. Case Study Research: Design and Methods. Thousand Oaks. IL. Sage Publications. 3rd ed.

Zhou, G., Y. Van Hui, and L. Liang. 2011. "Strategic alliance in freight consolidation." Transportation Research Part E: Logistics and Transportation Review 47 (1): 18-29. 
Figure 1 - The Scenario-Based Estimation Tool

Figure $2-$ The results of the first scenario

Figure 3 - The results of the sensitivity analysis

Figure 4 - The results of the second scenario 